\title{
Effects of Low Temperature and High Strain Rate on the Tensile Behaviors of High-Performance Energetic Composite
}

\author{
WANG Zhe Jun ${ }^{\mathrm{a}}$, QIANG Hong Fu' ${ }^{\mathrm{b}}$, WANG Guang ${ }^{\mathrm{c}}$ and ZHU Zhao Jun ${ }^{\mathrm{d}}$ \\ 601 Staff room, Xi' an Hi-Tech Institute, Xi' an 710025, China \\ aqinglongzaitian888@163.com, ${ }^{b}$ qianghf@126.com, ${ }^{c}$ wangbintai@126.com, ${ }^{\mathrm{d}}$ zhuzj@126.com
}

\begin{abstract}
To further study the effects of low temperature and high strain rate on the tensile behaviors of hydroxyl-terminated polybutadiene (HTPB) propellant, an INSTRON testing machine was applied for carrying out the uniaxial tensile tests at low temperatures and room temperature after storage at low temperatures. The strain rates are in the range of 0.40 to $85.71 \mathrm{~s}^{-1}$. Scanning electron microscope (SEM) was used for examining the failure mechanisms of HTPB propellant under the test conditions. The results reveal that HTPB propellant is still capable of large deformation at lower strain rates and low temperatures in the glass transition and glass state. The characteristics of stress-strain curves at room temperature after storage at low temperatures are the same with that directly obtained at room temperature. The effect of strain rate on the elastic modulus $E$ at various temperatures is almost the same. However, the effect of strain rate on the maximum tensile stress $\sigma_{m}$ becomes weak with decreasing temperature.

Furthermore, the strain $\varepsilon_{m}$ is nearly independence of the strain rate at higher strain rates and the lowest test temperature in glass state. Continuously decreasing temperature can more easily cause the extensive brittle fracture of AP particles, even at lower strain rates. The temperature changes from room temperature to low temperature and then from low temperature to room temperature in a short time cannot influence the failure mechanism of HTPB propellant at room temperature and high strain rate.
\end{abstract}

Keywords: low temperature, high strain rate, tensile behaviors, high-performance energetic composite

\section{Introduction}

Solid propellant is the typical high-performance energetic composite and its mechanical properties and failure mechanisms are sensitive to strain rate and temperature [1]. In service, solid rocket motor (SRM) is often subjected to different external stimuli, e.g. impact, ignition pressurization, causing the change of the mechanical properties and failure mechanisms of solid propellant [2]. Furthermore, in almost all cases, when the damage occurs in the solid propellant, an increase in burning surface of the propellant grain can result in malfunctioning 
or, in worst case, explosion of SRM [3]. Therefore, to ensure the propellant grain structural integrity and structural reliability of SRM, it is very important to study the behaviors of solid propellant under various loading conditions.

In the past decades, the study of behaviors of solid propellants under various loading conditions has drawn tremendous attention. Based on the tensile and compressive tests under quasi-static conditions $\left(<1 \mathrm{~s}^{-1}\right)$ and room temperature, Ren et al. had analyzed the differences of mechanical properties for a hydroxyl-terminated polybutadiene (HTPB) propellant under different stress states [4]. The influence of components on the low temperature mechanical properties of solid propellants under quasi-static conditions had been investigated by Mohamed et al [5-6]. Zhang et al. had conducted quasi-static tensile tests at low temperatures $(298-223 \mathrm{~K})$ and room temperature after storage at low temperatures to study the low temperature mechanical properties of HTPB propellant [7]. Using a conventional universal testing machine and a modified split Hopkinson pressure bar (SHPB) apparatus, Sun et al. had studied the compressive behaviors of a composite modified doublebase (CMDB) propellant at low temperatures $(298-233 \mathrm{~K})$ and different strain rates $\left(10^{-4}-10^{3} \mathrm{~s}^{-1}\right)$ [8]. However, up to now, to the best of our knowledge, there are few analyses on the high strain rate $\left(1-10^{2} \mathrm{~s}^{-1}\right)$ behaviors of solid propellants at low temperatures. In our previous work [9-10], a new test method had been proposed to study the tensile behaviors of HTPB propellant at those loading conditions. Furthermore, the mechanical properties, failure mechanisms and constitutive model of the propellant had been also investigated based on the test results. However, the tensile behaviors of HTPB propellant at lower temperatures $(<233$ $\mathrm{K})$ and higher strain rates $\left(>50 \mathrm{~s}^{-1}\right)$ are still unclear, especially in the glass transition and glass state. In addition, the high strain rate $\left(1-10^{2} \mathrm{~s}^{-1}\right)$ tensile behaviors of HTPB propellant at room temperature after storage at low temperatures have never been investigated before. Therefore, further investigation is required to study the effects of low temperature and high strain rate on the tensile behaviors of HTPB propellant.

In the present investigation, uniaxial high strain rate tensile tests at low temperatures and room temperature after storage at low temperatures were performed to further study the behaviors of HTPB propellant. Scanning electron microscope (SEM) was used for examining the failure mechanisms of HTPB propellant under the test conditions. Based on the test results, the effect of the different loading conditions on the mechanical properties and failure mechanisms of HTPB propellant was discussed. Finally, the correlation between the mechanical properties and failure mechanisms of HTPB propellant was also analyzed.

\section{Material and Test Methods}

The material used here comprises of $88 \mathrm{wt}-\%$ mixture of ammonium perchlorate (AP) and aluminum particles, $7.852 \mathrm{wt} \%$ of HTPB polymer binder and curing agent, and 4.148 wt- $\%$ others. As measured in our previous work [10], the glass transition temperature for this propellant is about $214 \mathrm{~K}$. According to the Chinese aerospace industry standard of P. R. C, QJ 924-85, the dimensions of the test samples were determined to be dumbbell-slat shape, as shown in Figure 1. Uniaxial tensile tests were conducted using the classical testing machine INSTRON VHS 160/100-20 at four different strain rates in this investigation, which is 0.40 , $4.00,14.29,85.71 \mathrm{~s}^{-1}(0.028 \mathrm{~m} / \mathrm{s}, 0.280 \mathrm{~m} / \mathrm{s}, 1.000 \mathrm{~m} / \mathrm{s}, 6.000 \mathrm{~m} / \mathrm{s})$, respectively. The samples were tested in quintuplicate at room temperature (298 K) and low temperatures (243-213 K) of each strain rate. All stress-strain curves analyzed later were the average of the five data sets. In this investigation, two different types of temperature conditions were considered. Firstly, the samples were conditioned at the required temperature for $1 \mathrm{~h}$ and were then tested directly until they fractured. Secondly, the samples were conditioned at $243 \mathrm{~K}$ and $223 \mathrm{~K}$ for $4 \mathrm{~h}$ and were then removed to be desiccated at room temperature for $24 \mathrm{~h}$ and equilibrated to 
room temperature. Finally, the samples were tested at room temperature until they fractured. Prior to testing, the samples were all sealed with plastic film. The humidity of the temperature chamber and the air humidity were all very low.

A Quanta 600FEG SEM was used for examining the failure mechanisms of HTPB propellant under the test conditions. Samples were mounted using a conductive paint onto SEM stubs and sputter coated with a thin layer of gold prior to examination.

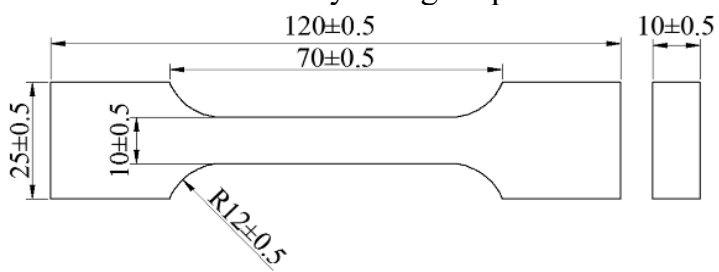

Figure 1. Schematic diagram of the uniaxial tensile test sample $(\mathrm{mm})$

\section{Results and Discussion}

\subsection{Stress-strain Behaviors.}

Figure 2 shows the typical tensile stress-strain curves of HTPB propellant at various temperatures and strain rates. From Figure 2, it can be observed that the strain rate and temperature dependence of the tensile behaviors for HTPB propellant at lower temperatures and higher strain rate is still obvious. When increasing strain rate or decreasing temperature, the stress increases significantly. Furthermore, the characteristics of stress-strain curves under various loading conditions are remarkably different. At all test temperatures and lower strain rates, after a rather straight initial part, the shape of stress-strain curves shows a sharp bend and then the stress continues to increase gradually over a prolonged strain range before rupture finally occurs. HTPB propellant is still capable of large deformation at lower strain rates and low temperatures in the glass transition and glass state. At room temperature and the highest strain rate, there is a plateau region in the stress-strain curve before a near linear relationship of stress-strain is again established and kept up to the point of maximum tensile stress and eventual sample fracture. However, the tensile stress quickly reaches its maximum value at small strain and then drops rapidly at lower temperatures and higher strain rates. The characteristics of stress-strain curves at room temperature after storage at low temperatures are the same with that directly obtained at room temperature (Figure 2(a)), which is different from that under quasi-static tensile tests in previous research [7]. Because of these, the effects of strain rate and temperature on the mechanical parameters at room temperature after storage at low temperatures would not be separately analyzed in the following section.

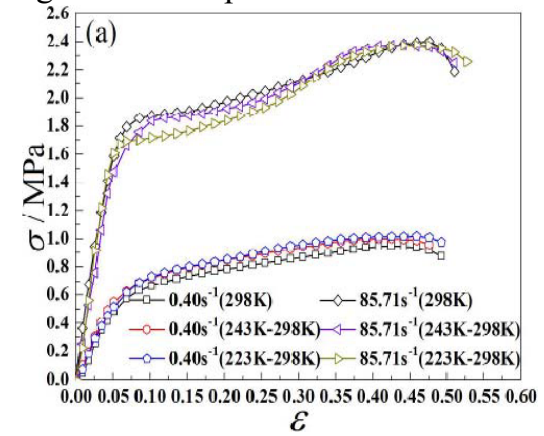

(a) $298 \mathrm{~K}$

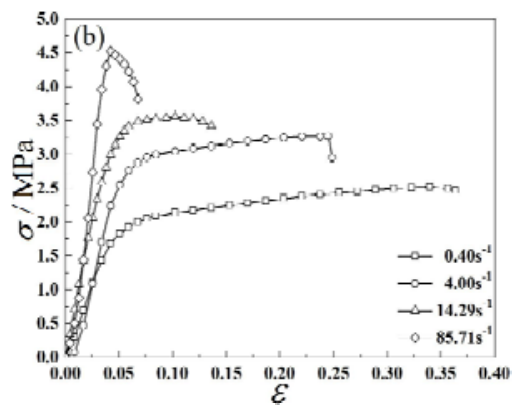

(b) $223 \mathrm{~K}$ 


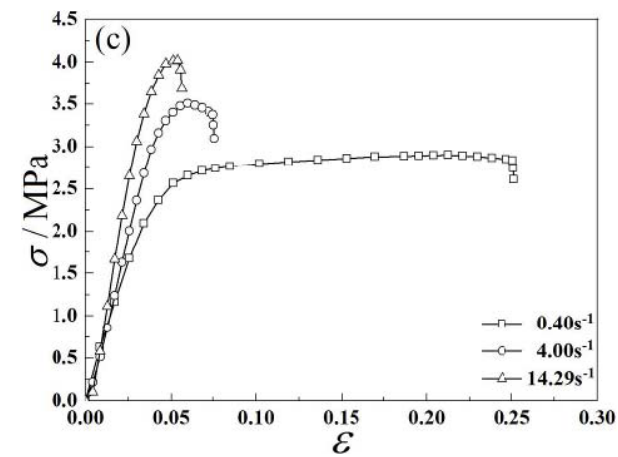

(c) $213 \mathrm{~K}$

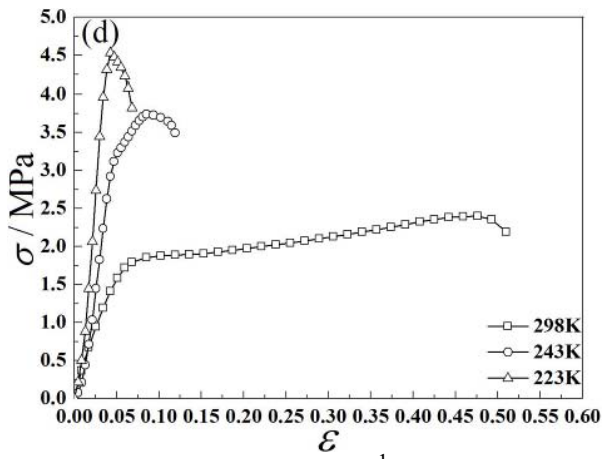

(d) $85.71 \mathrm{~s}^{-1}$

Figure 2 .Tensile stress-strain curves of HTPB propellant at various temperatures and strain rates

\subsection{Mechanical Properties.}

According to the obtained test data and the defining method used in our previous work [10], the elastic modulus $E$, maximum tensile stress $\sigma_{m}$ and strain at maximum tensile stress $\varepsilon_{m}$ were obtained. These mechanical parameters with respect to strain rate and temperature are shown in Figure 3.

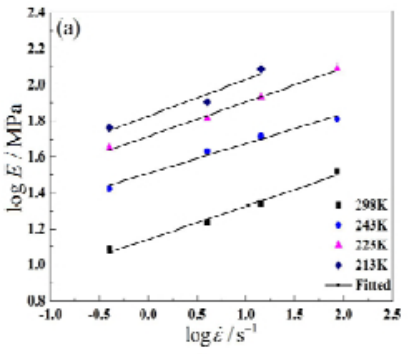

(a) Elastic modulus

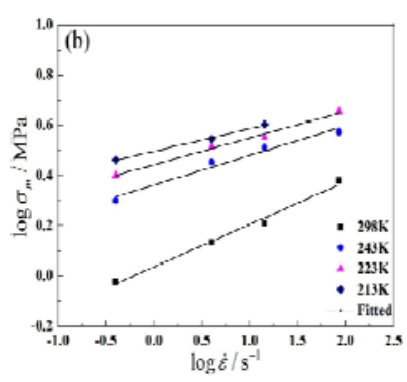

(b) Maximum tensile stress

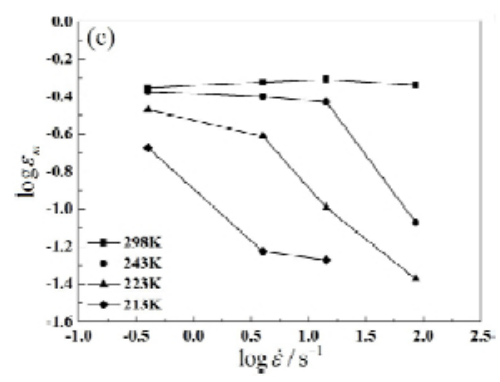

(c) Strain at maximum tensile stress

Figure 3 Mechanical parameters of HTPB propellant vs. logarithmic strain rate at various test temperatures

As shown in Figure 3, both $E$ and $\sigma_{m}$ increase as a linear-log function of strain rate at various temperatures, and decreasing temperature can induce a bigger values of these mechanical parameters. The fitted lines of the elastic modulus $E$ at various temperatures are approximately parallel, which indicates that the effect of strain rate on this parameter at various temperatures is almost the same. However, the slope of the fitted lines for the maximum tensile stress $\sigma_{m}$ at lower temperatures is smaller, which indicates that the effect of strain rate on this parameter becomes weak with decreasing temperature. Furthermore, it can be seen from Figure 3(c) that the strain $\varepsilon_{m}$ decreases with decreasing temperature. The effect of strain rate on this parameter is more obvious as the temperature decreases. However, this parameter is nearly independence of the strain rate at higher strain rates and the lowest test temperature in glass transition. 


\subsection{Failure Mechanisms.}

Figure 4 present the typical SEM images of the tensile fracture surfaces for HTPB propellant under the test conditions. From Figure 4(a) it is clear that all interfaces between the filled particles and matrix are undamaged at lower strain rate and very low temperature in the glass transition state, whereas lots of AP particles fracture, which is more severe than that at $233 \mathrm{~K}$ and $0.40 \mathrm{~s}^{-1}$ in our previous work [10]. Therefore, Figure 4(a) reveals that continuously decreasing temperature can more easily cause the extensive brittle fracture of AP particles, even at lower strain rates. Furthermore, HTPB propellant becomes stiffer at lower temperature. Based on the above discussions, the effect of strain rate on the stress $\sigma_{m}$ and strain $\varepsilon_{m}$ is less obvious at the lowest temperature and higher strain rates in this investigation, because the variation of these mechanical parameters for HTPB propellant with strain rate and temperature is closely related to its properties and failure mechanisms under various loading conditions.

From Figure 4(b) and 4(c) it is clear that the interfaces between the filled particles and matrix are nearly intact at room temperature after storage at low temperatures and the strain rate range analyzed in this investigation, whereas some larger AP particles fractures occur. The failure mechanism of HTPB propellant under these loading conditions is the same with that at room temperature in our previous work [10], which further indicates that the temperature changes from room temperature to low temperature and then from low temperature to room temperature in a short time cannot influence the failure mechanism of HTPB propellant at room temperature and high strain rate. This is may be because of the following reasons. As stated in the previous research [11], decreasing temperature can increase the dewetting stress between the filled particles and matrix for HTPB propellant. In addition, the fracture stress of a crystal is generally high. Therefore, only the temperature change in a short time cannot lead to the damage of the propellant in the microstructure.

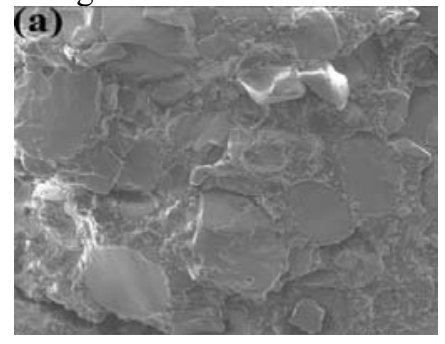

(a) $223 \mathrm{~K}$ and $0.40 \mathrm{~s}^{-1}$

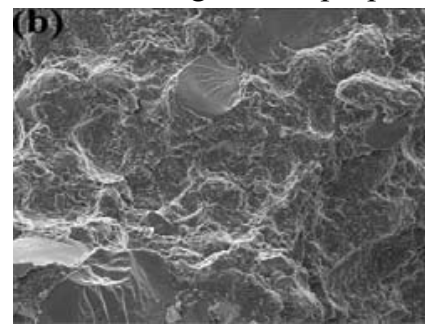

(b) $298 \mathrm{~K}$ and $85.71 \mathrm{~s}^{-1}$ after storage $243 \mathrm{~K}$

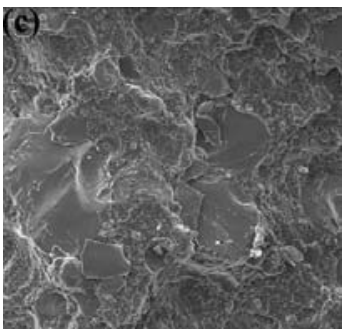

(c) $298 \mathrm{~K}$ and $85.71 \mathrm{~s}^{-1}$ after storage $223 \mathrm{~K}$

Figure 4 SEM images of HTPB propellant under different loading conditions $(\times 200)$

\section{Summary}

Based on an INSTRON testing machine and SEM, the effects of low temperature and high strain rate on the tensile behaviors of HTPB propellant were further investigated. The results reveal that the strain rate and temperature dependence of the tensile behaviors for HTPB propellant at higher strain rate $\left(>50 \mathrm{~s}^{-1}\right)$ and lower temperatures $(<233 \mathrm{~K})$ is still obvious. HTPB propellant is still capable of large deformation at lower strain rates and low temperatures in the glass transition and glass state, which indicates that the low temperature mechanical properties of this propellant is good. The characteristics of stress-strain curves at room temperature after storage at low temperatures are the same with that directly obtained at room temperature. 
The effect of strain rate on the elastic modulus $E$ at various temperatures is almost the same. However, the effect of strain rate on the maximum tensile stress $\sigma_{m}$ becomes weak with decreasing temperature. Furthermore, the strain $\varepsilon_{m}$ decreases with decreasing temperature. The effect of strain rate on this parameter is more obvious as the temperature decreases. However, this parameter is nearly independence of the strain rate at higher strain rates and the lowest test temperature in glass state.

The variation of the above mechanical properties for HTPB propellant with temperature and strain rate is closely related to its properties and failure mechanisms under various loading conditions. Continuously decreasing temperature can more easily cause the extensive brittle fracture of AP particles, even at lower strain rates. The temperature changes from room temperature to low temperature and then from low temperature to room temperature in a short time cannot influence the failure mechanism of HTPB propellant at room temperature and high strain rate.

The results obtained in this investigation are very helpful for fully understanding the behaviors of solid propellants under various loading conditions and can provide the theoretical basis for analyzing the propellant grain structural integrity and structural reliability of SRM at low temperatures and high strain rates.

\section{References}

1. R. Zalewski, T. Wolszakiewicz, Analysis of uniaxial tensile tests for homogeneous solid propellants under various loading conditions, Cent. Eur. J. Energ. Mater. 8 (2011) 223-231.

2. S.Y. Ho, Viscoelastic response of solid rocket motor components for service life assessment, J. Mater. Sci. 32 (1997) 5155-5161.

3. H.T. Chu, J.H. Chou, Effect of cooling load on the safety factor of propellant grains, J. Propul. Power 1 (2013) 27-33.

4. P. Ren, X. Hou, G.R. He, J. Gao, T.S. He, Comparative research of tensile and compressive modulus of composite solid propellant for solid rocket motor, J. Astronautics 31 (2010) 2354-2359.

5. A. Mohamed, F. Gholamian, A.R. Zarei, Investigation of composite solid propellants based on nitrated hydroxyl terminated polybutadiene binder, J. Propul. Power 30 (2014) 862-864.

6. J.L. De La Fuente, M. Fernández-García, M.L. Cerrada, Viscoelastic behavior in a hydroxyl-terminated polybutadiene gum and its highly filled composites: effect of the type of filler on the relaxation processes, J. Appl. Polym. Sci. 88 (2003) 1705-1712.

7. X. Zhang, X. Chang, S. Zhang, J. Zhu, Experimental study on low temperature mechanical properties of HTPB propellant, Appl. Math. Mech. 310 (2013) 124-128.

8. C. Sun, J. Xu, X. Chen, J. Zheng, Y. Zheng, W. Wang, Strain rate and temperature dependence of the compressive behavior of a composite modified double-base propellant, Mech. Mater. 89 (2015) 35-46.

9. Z. Wang, H. Qiang, G. Wang, Q. Huang, Tensile mechanical properties and constitutive model for HTPB propellant at low temperature and high strain rate, J. Appl. Polym. Sci. 132 (2015) doi: 10.1002/APP.42104.

10. Z. Wang, H. Qiang, G. Wang, Experimental investigation on high strain rate tensile behaviors of HTPB propellant at low temperatures, Propellants Explos. Pyrotech. 2015, doi: 10.1002/prep.201500030.

11. S.J.P. Palmer, J.E. Field, J.M. Huntley, Deformation, strengths and strains to failure of polymer bonded explosives, Proc. R. Soc. London A 440 (1993) 399-419. 